\title{
Author Correction: Improving pharmacogenetic prediction of extrapyramidal symptoms induced by antipsychotics
}

Daniel Boloc ${ }^{1}$, Anna Gortat ${ }^{2}$, Jia Qi Cheng-Zhang², Susana García-Cerro², Natalia Rodríguez², Mara Parellada ${ }^{3,4}$, Jeronimo Saiz-Ruiz, ${ }^{3,5}$, Manolo J. Cuesta ${ }^{3,6}$, Patricia Gassó ${ }^{2}$, Amalia Lafuente ${ }^{2,3,7}$, Miquel Bernardo ${ }^{1,3,7,8}$ and Sergi Mas $\mathbb{1}^{2,3,7}$

\section{Correction to: Transl. Psychiatry}

https://doi.org/10.1038/s41398-018-0330-4

Published online 13 December 2018.

One of the funding sources (FEDER-Unión Europea) was not previously acknowledged in this Article. This study was supported by the Spanish Ministry of Health,
Instituto de Salud Carlos III (FIS, Fondo de Investigacion Sanitaria PI13/00812, PI16/0122) and FEDER-Unión Europea.

Published online: 02 May 2019

\footnotetext{
Correspondence: Miquel Bernardo (bernardo@clinic.ub.es) or

Sergi Mas (sergimash@ub.edu)

'Department of Medicine, University of Barcelona, Barcelona, Spain

${ }^{2}$ Department of Clinical Foundations, Pharmacology Unit, University of

Barcelona, Barcelona, Spain

${ }^{3}$ Centro de Investigación Biomédica en Red de Salud Mental (CIBERSAM),

Carlos III Health Institute, Barcelona, Spain

${ }^{4}$ Child and Adolescent Psychiatry Department, Hospital General Universitario Gregorio Marañón, School of Medicine, Universidad Complutense, liSGM, Madrid, Spain

${ }^{5}$ Hospital Ramon y Cajal, Universidad de Alcala, IRYCIS, Madrid, Spain

${ }^{6}$ Department of Psychiatry, Complejo Hospitalario de Navarra, Instituto de Investigación Sanitaria de Navarra (IdiSNA), Pamplona, Spain

${ }^{7}$ The August Pi i Sunyer Biomedical Research Institute (IDIBAPS), Barcelona, Spain

${ }^{8}$ Barcelona Clínic Schizophrenia Unit, Hospital Clínic de Barcelona, Barcelona,

Spain

These authors contributed equally: Daniel Boloc, Anna Gortat
}

(ㅇ The Author(s) 2019

(c) Open Access This article is licensed under a Creative Commons Attribution 4.0 International License, which permits use, sharing, adaptation, distribution and reproduction in any medium or format, as long as you give appropriate credit to the original author(s) and the source, provide a link to the Creative Commons license, and indicate if changes were made. The images or other third party material in this article are included in the article's Creative Commons license, unless indicated otherwise in a credit line to the material. If material is not included in the article's Creative Commons license and your intended use is not permitted by statutory regulation or exceeds the permitted use, you will need to obtain permission directly from the copyright holder. To view a copy of this license, visit http://creativecommons.org/licenses/by/4.0/. 